\title{
Placenta percreta - a management dilemma: an institutional experience and review of the literature
}

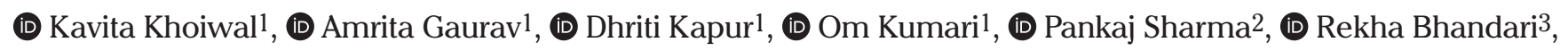 \\ (D) Jaya Chaturvedi ${ }^{1}$ \\ 1Department of Obstetrics and Gynecology, All India Institute of Medical Sciences, Rishikesh, India \\ 2Department of Radiology, All India Institute of Medical Sciences, Rishikesh, India \\ 3Department of Pathology, All India Institute of Medical Sciences, Rishikesh, India
}

\section{Abstract}

Objective: Placenta percreta is an extremely high-risk obstetric condition often associated with significant maternal morbidity and mortality. To date, there is no consensus on its management. This article aimed to identify an optimum management option to improve maternal outcomes in patients with placenta percreta.

Material and Methods: This was an observational study conducted at a tertiary care institute from October 2019 to June 2020 . A well-defined plan of preoperative, bilateral, uterine artery catheter placement, cesarean delivery (CD) of the baby followed by uterine artery embolization (UAE), and elective delayed hysterectomy after 2-4 weeks, was made by a multidisciplinary team. Demographic variables such as age, parity, period of gestation, presenting complaints, imaging findings, mode of management, intraoperative findings, blood loss, the requirement for blood and blood products, and complications were noted.

Results: We encountered seven cases of placenta percreta over a period of nine months. UAE was performed in 6/7 patients. UAE was not performed in one patient as she presented to the emergency department in shock. Elective delayed hysterectomy was performed after $2-4$ weeks in three patients, three patients required emergency hysterectomy (two during CD and one on the seventh postoperative day) and one patient was managed conservatively by leaving the placenta in situ after CD and UAE. Patients who underwent UAE had notably less intraoperative blood loss and requirement of blood and blood products than the patient who could not receive UAE. During cesarean hysterectomy, blood loss was $1,700 \mathrm{~mL}$ in embolized (case 4) vs 3,000 $\mathrm{mL}$ in unembolized patient (case 7). In embolized patients, the median blood loss during CD (case 1,2,3,5,6) was $200 \mathrm{~mL}$ (interquartile range: $165-200 \mathrm{~mL}$ ) and during delayed elective hysterectomy (case 1,3,5) was 150 mL (range: 125-225 $\mathrm{mL}$ ). Blood loss in case 2 was $1,000 \mathrm{~mL}$ during emergency hysterectomy on the $7^{\text {th }}$ day of $\mathrm{CD}$ and UAE. The blood loss was appreciably higher in patients who underwent immediate cesarean hysterectomy rather than elective delayed hysterectomy.

Conclusion: Placenta percreta, if not managed in a preplanned manner, may lead to disastrous maternal outcomes. Prophylactic devascularization during $\mathrm{CD}$ and leaving the placenta in situ followed by elective delayed hysterectomy, might be a reasonable management option in most severe cases of placenta percreta. (J Turk Ger Gynecol Assoc 2020; 21: 228-35)

Keywords: Placenta percreta, uterine artery embolization, elective delayed hysterectomy, immediate cesarean hysterectomy

Received: 22 June, 2020 Accepted: 13 October, 2020

\section{Introduction}

Placenta percreta is one of the most dreaded obstetric complications. The overall incidence of placenta percreta is low at $5 \%$ of all placenta accreta spectrum (PAS) cases, but the incidence is currently rising owing to an increased rate of cesarean deliveries (CD). The reported incidence of PAS is 1 in 300 (1) and the risk of bladder invasion is much lower (1 in 10,000 pregnancies) (2). PAS is associated with significant maternal morbidity (24-67\%) including intractable hem-orrhage (2-4 liters), bladder injury, a requirement for massive blood transfusion, disseminated intravascular coagulopathy (DIC), thromboembolism, systemic infection, sometimes repeat surgeries (3) and mortality (7\%) (4). The severity of complications 
increases with the severity of placental invasion. Therefore, placenta percreta is the most dangerous manifestation of PAS.

To date, there is no consensus on the management of these cases. However, cesarean hysterectomy is the widely accepted management for PAS (5). In contrast, a conservative management option includes leaving the placenta in situ for spontaneous resorption, but it is associated with increased morbidity, high risk of infection, hemorrhage, and a requirement for emergency hysterectomy in $58 \%$ of cases within nine months of cesarean section (6). Moreover, in cases of placenta percreta, owing to the high morbidity and mortality rate, it seems reasonable to utilize alternative options such as delayed hysterectomy with or without prophylactic devascularization (7). The debate continues between a conservative or surgical approach, and immediate cesarean hysterectomy or elective delayed hysterectomy.

We report a series of seven cases of placenta percreta managed successfully at our institute. The aim was to identify an optimum management option to improve maternal outcomes in patients with placenta percreta based on the available literature.

\section{Material and Methods}

This was an observational study conducted at the department of obstetrics and gynaecology of a tertiary care institute. Being a referral center and despite the low prevalence, seven cases of placenta percreta were encountered over a period of nine months, from October 2019 to June 2020. All cases in which the placenta was found to be invading the entire uterine wall, penetrating the uterine serosa, and encroaching adjacent organs, such as the bladder or parametrium were designated placenta percreta. The initial method of diagnosis of placenta percreta was ultrasound (USG), subsequently confirmed with magnetic resonance imaging (MRI).

On referral of the first case, a multidisciplinary team including a senior obstetrician, interventional radiologist, urologist, transfusion medicine, neonatologist, critical care, and anesthetist was formed to avoid or minimize intraoperative hemorrhage and postoperative complications. After thorough discussion of the pros and cons of the conservative and surgical approach, a well-defined plan of preoperative bilateral uterine artery catheter placement, CD of the baby followed by uterine artery embolization (UAE) and elective delayed hysterectomy after 2-4 weeks (Figure 1) was formed. A transverse incision on the uterine fundus was planned to deliver the baby during cesarean section, as lower segment transverse or vertical incision can directly transect the placenta (8). Similarly, a vertical incision over the upper uterine segment may extend to the placental margins and lead to catastrophic hemorrhage, resulting in increased maternal-fetal morbidity and mortality.
A written and informed consent was taken from all patients. The study was reviewed and approved by the Institutional Ethical Committee (approval number: AIIMS/IEC/20/341) of All India Institute of Medical Sciences Rishikesh.

Antenatal booking status, referral, demographic variables such as age, parity, period of gestation, presenting complaints, imaging findings, mode of management, intraoperative findings, blood loss, a requirement of blood and blood products, and complications were noted.

\section{Statistical analysis}

Baseline demographic characteristics, intraoperative, and postoperative outcome variables of all cases of placenta percreta were noted in a tabular form. Descriptive statistics were used to calculate simple frequency, percentage, and proportion. Intraoperative blood loss was calculated as median with interquartile range.

\section{Results}

Table 1 shows baseline demographic characteristics, imaging, and intra-operative and post-operative variables. All patients

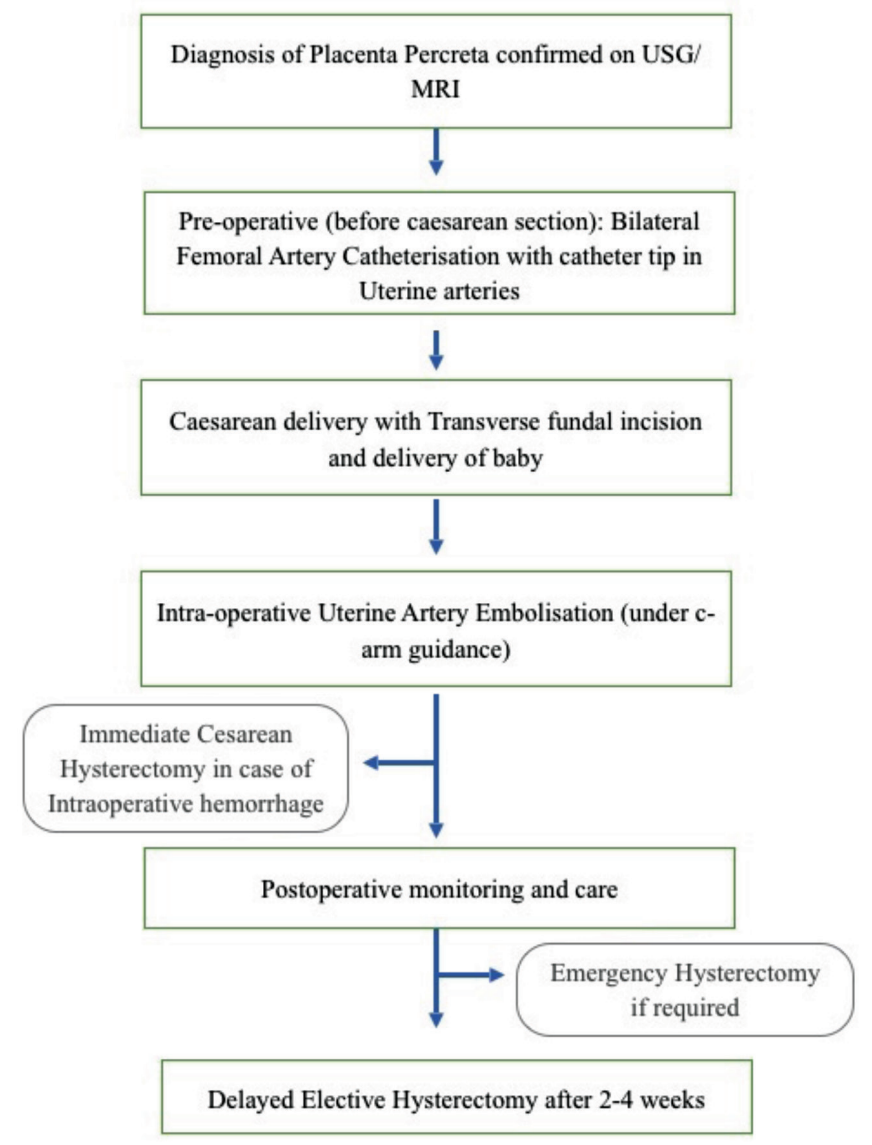

Figure 1. Algorithm for management of placenta percreta at our centre

USG: Ultrasound, MRI: Magnetic resonance imaging 


\begin{tabular}{|c|c|c|c|c|c|c|c|}
\hline 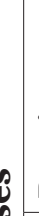 & 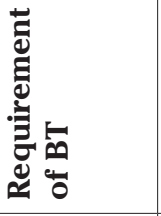 & , & 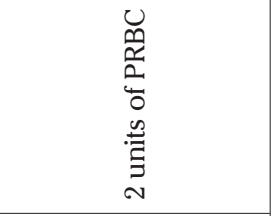 & . & 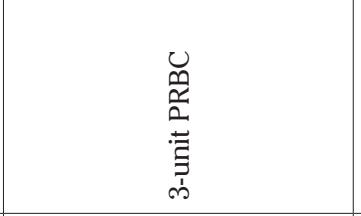 & ' & . \\
\hline ב. & 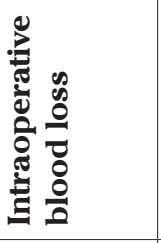 & 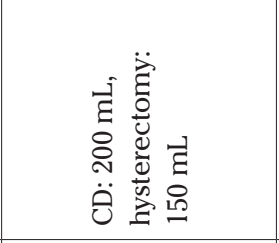 & 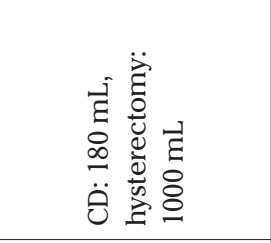 & 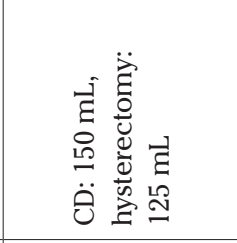 & 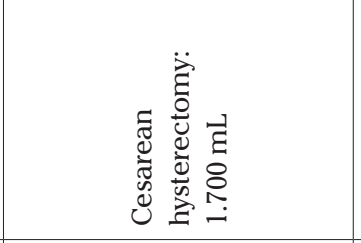 & 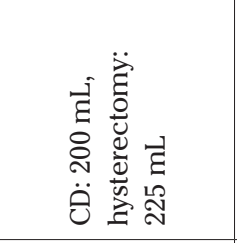 & $\begin{array}{l}\vec{\Xi} \\
\stackrel{̊}{0} \\
\ddot{0}\end{array}$ \\
\hline 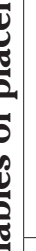 & 造 & $\begin{array}{l}0 \\
\tilde{z}\end{array}$ & $\frac{T}{2}$ & 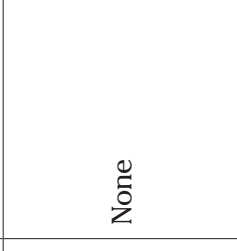 & 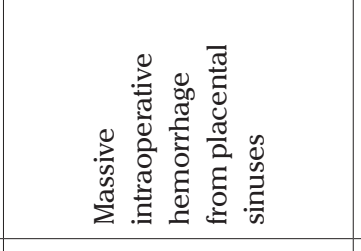 & İ & $\begin{array}{l}0 \\
\tilde{z}\end{array}$ \\
\hline & 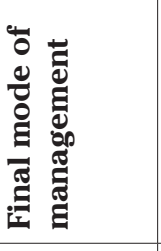 & 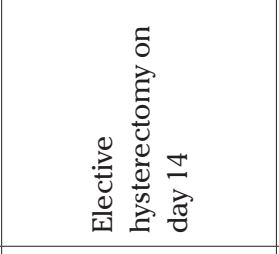 & 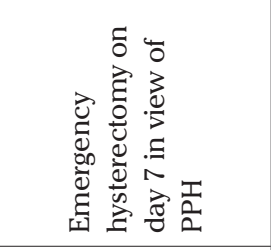 & 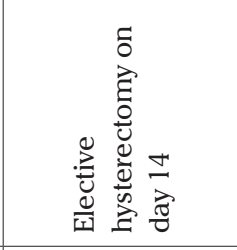 & 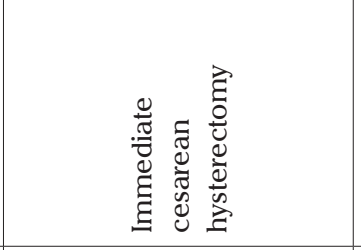 & 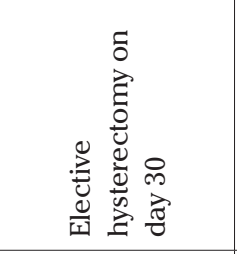 & 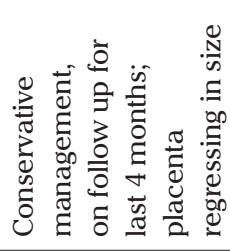 \\
\hline & 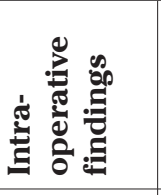 & 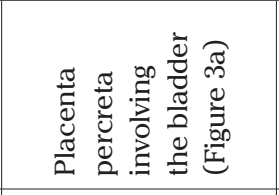 & 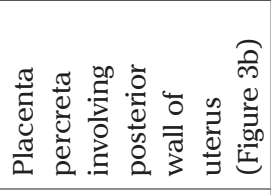 & 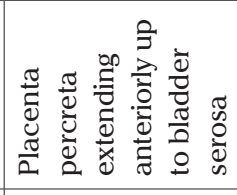 & 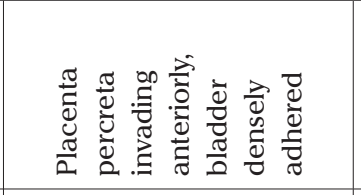 & 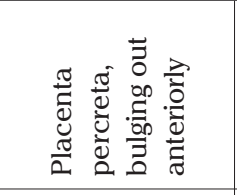 & 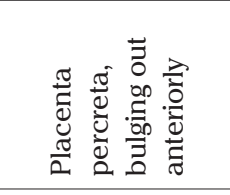 \\
\hline & 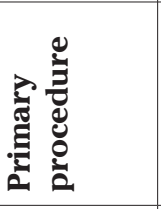 & 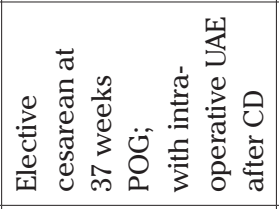 & 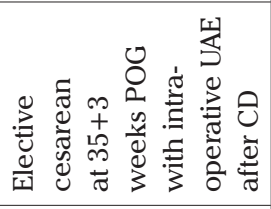 & 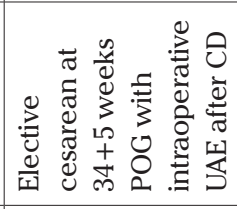 & 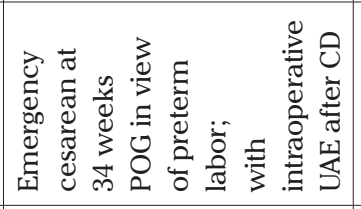 & 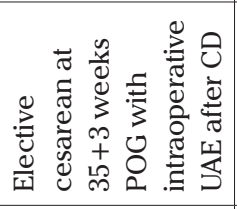 & 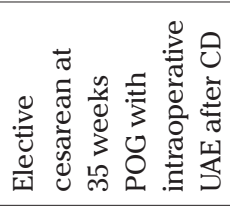 \\
\hline & 罗 & 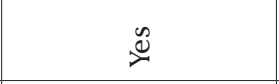 & 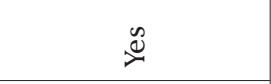 & 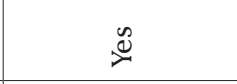 & 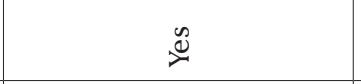 & 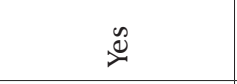 & 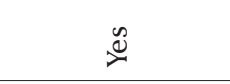 \\
\hline & 翟 & 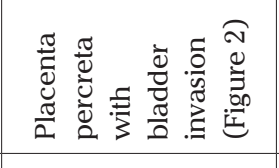 & 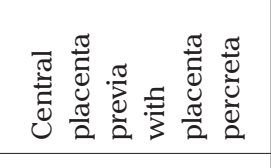 & 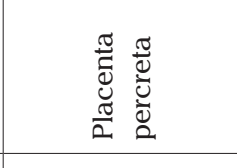 & 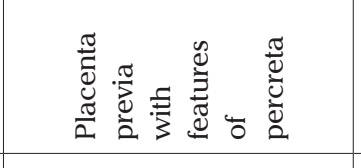 & 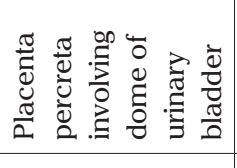 & 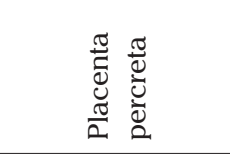 \\
\hline & 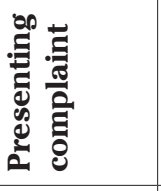 & 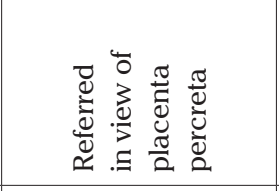 & 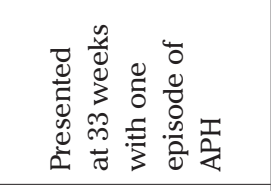 & 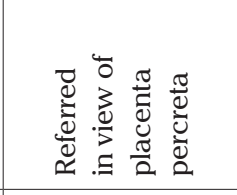 & 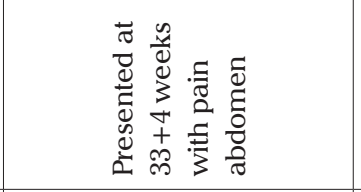 & 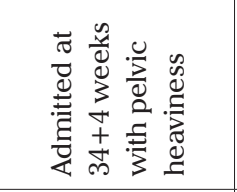 & 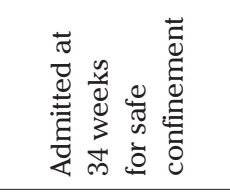 \\
\hline & 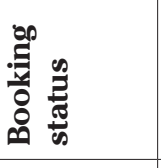 & 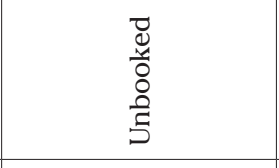 & 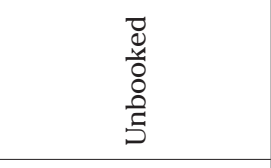 & 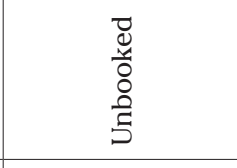 & 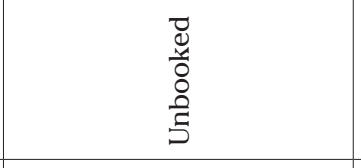 & 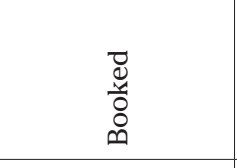 & 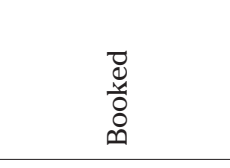 \\
\hline & 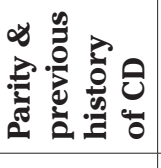 & 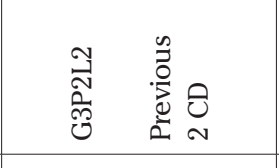 & 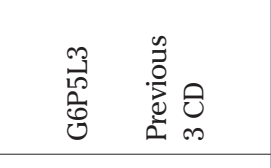 & 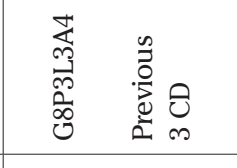 & 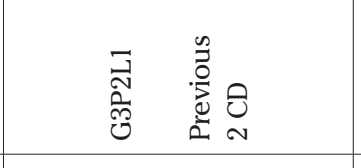 & 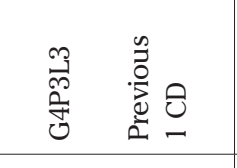 & 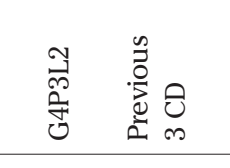 \\
\hline$\dot{\dot{y}}$ & 血 & চ & లి & $\dot{m}$ & চ & চे & : \\
\hline 8 & $\dot{\infty} \dot{z}$ & - & N & $\infty$ & $\sigma$ & ما & 0 \\
\hline
\end{tabular}




\begin{tabular}{|c|c|c|}
\hline 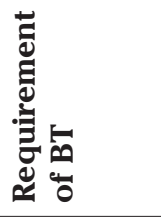 & 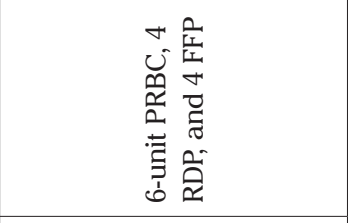 & 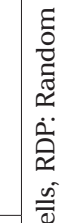 \\
\hline 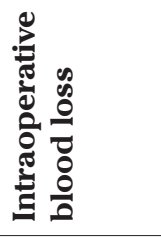 & 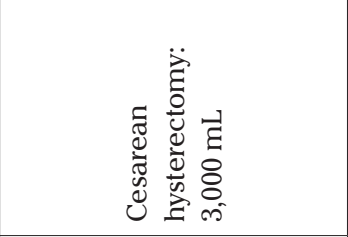 & 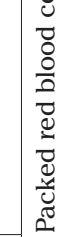 \\
\hline 递 & 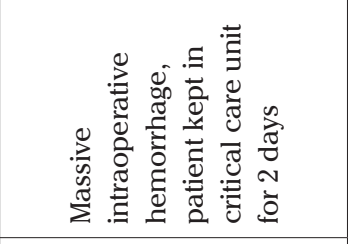 & 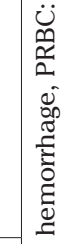 \\
\hline 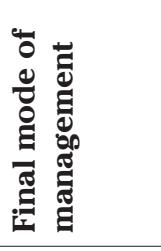 & 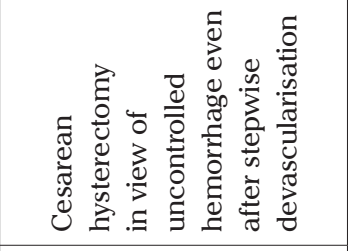 & 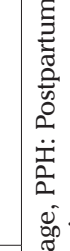 \\
\hline 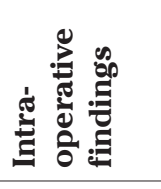 & 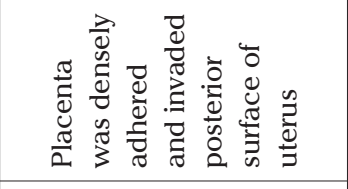 & 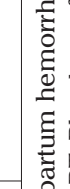 \\
\hline 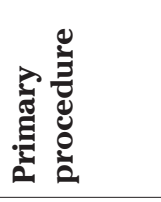 & 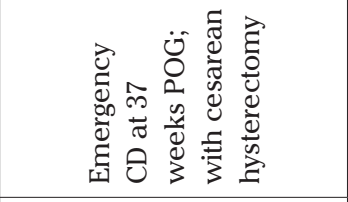 & 8 \\
\hline 䛼 & $\stackrel{0}{z}$ & \\
\hline 离 & 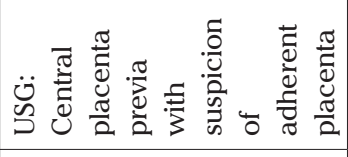 & 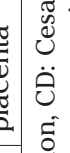 \\
\hline 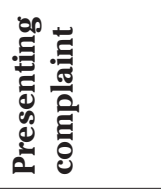 & 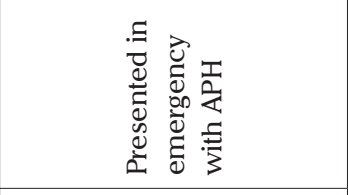 & 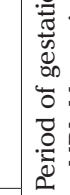 \\
\hline 兽 & 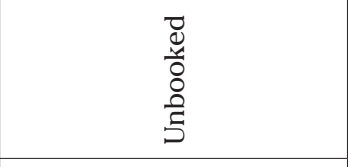 & 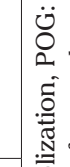 \\
\hline 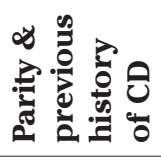 & 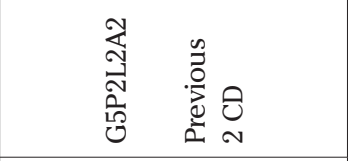 & 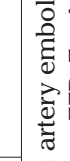 \\
\hline 总 & లి & \\
\hline$\dot{\boldsymbol{n}} \dot{\mathrm{z}}$ & r & \\
\hline
\end{tabular}

were young, with age ranging from 29 to 34 years. Most of the patients (5/7) were unbooked and either referred or presented to the emergency department. Planned elective CDs were performed at 34-36 weeks of gestation, with the exceptions of case 1 and case 7 when CD was performed at approximately 37 weeks, as they presented in late gestation (Table 1). Figure 2 shows MRI and cystoscopic image of case 1 .

UAE was performed in 6/7 (85.7\%) patients as per our protocol. On the day of $\mathrm{CD}$, bilateral femoral arteries were catheterized, with catheter tips placed bilaterally on uterine arteries under USG guidance. The patient was then shifted to the operating theatre for CD. General anesthesia was administered, and the abdomen opened in layers under asepsis. Intraoperative findings of case 1 and case 2 are shown in Figure 3. A transverse fundal incision was made to deliver the baby, cord clamped, and cut. No oxytocics were given. Signs of spontaneous placental separation were awaited. In the absence of such signs the placenta was left in situ. Then the interventional radiologist, in the operating theatre itself, confirmed the position of catheter tips on bilateral uterine arteries under $\mathrm{C}$-arm guidance with subsequent embolization with gel foam until stasis was achieved. Case 4 required immediate cesarean
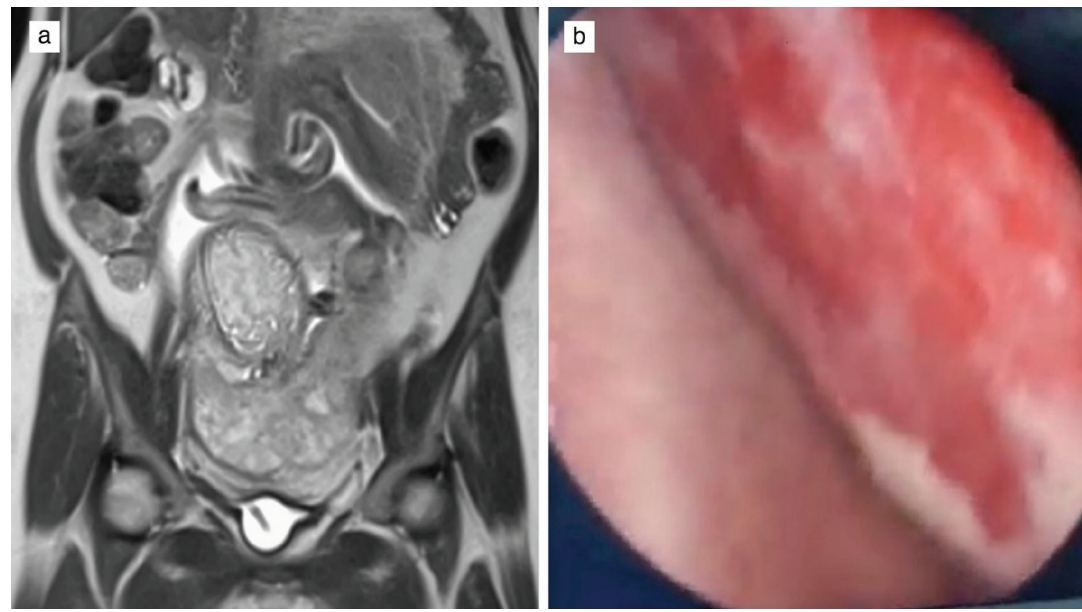

Figure 2. (a) T2 weighted magnetic resonance imaging (coronal section) showing placenta invading through the lower uterine segment reaching up to bladder serosa; (b) Cystoscopy showing placental bulge with intact bladder mucosa
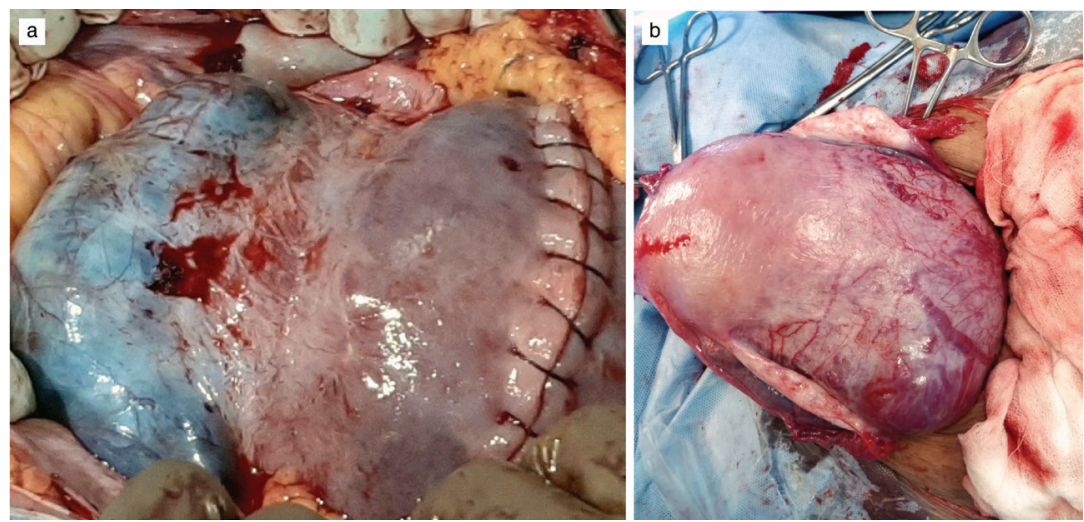

Figure 3. Intraoperative image of showing placenta percreta with an anterior bulge in case 1 (a) and a posterior bulge in case 2 (b) 
hysterectomy because of massive hemorrhage from placental sinuses. In all other cases, after ensuring that there was no bleeding from the placental site and vagina, the uterus was closed followed by the abdomen. All surgeries were performed by the same surgeons.

Every patient was closely observed in the post-operative period. Case 2 developed significant postpartum hemorrhage (PPH) on the seventh day after surgery and was taken for emergency hysterectomy during which no intraoperative complications were faced. Elective delayed hysterectomy was successfully performed on the $14^{\text {th }}$ day in cases 1 and 3 and on the $30^{\text {th }}$ day of $\mathrm{CD}$ in case 5 . Case 6 was keen for conservative management and has thus been kept on regular follow up for the last four months. Her USG suggested a regressed placenta.

UAE could not be performed in case 7 as she presented to the emergency department at midnight with antepartum hemorrhage and features of shock. Therefore, she was immediately taken for cesarean hysterectomy. Intraoperative blood loss was significant (approximately 3,000 mL) and
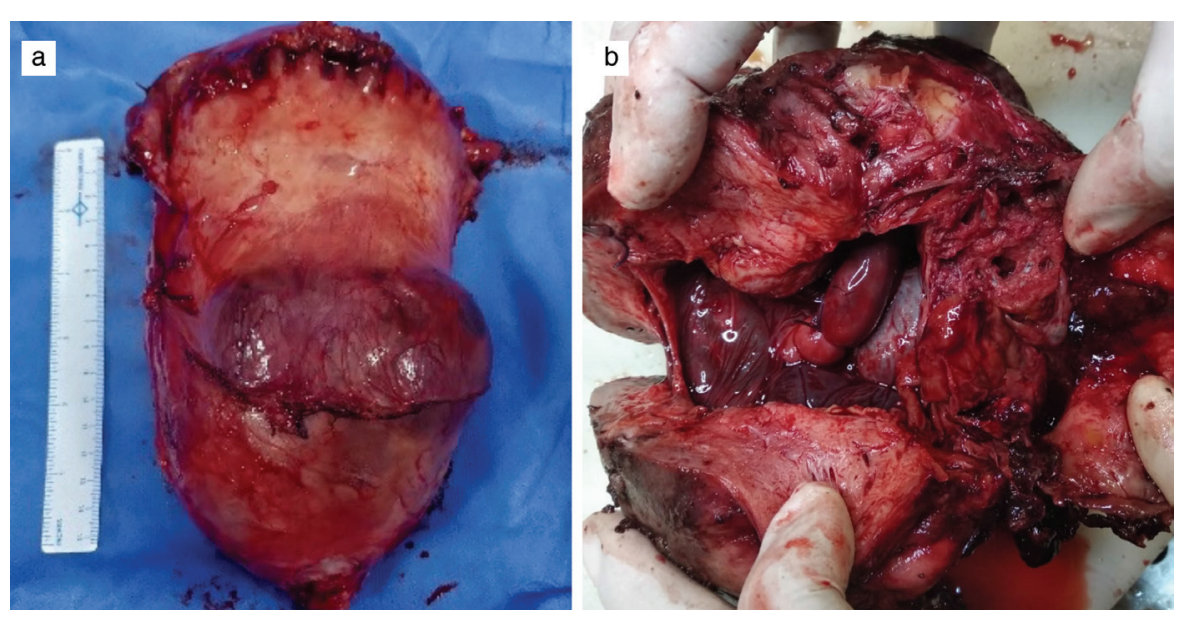

Figure 4. Hysterectomy specimen showing placenta percreta in case 1 (a) and 2 (b)

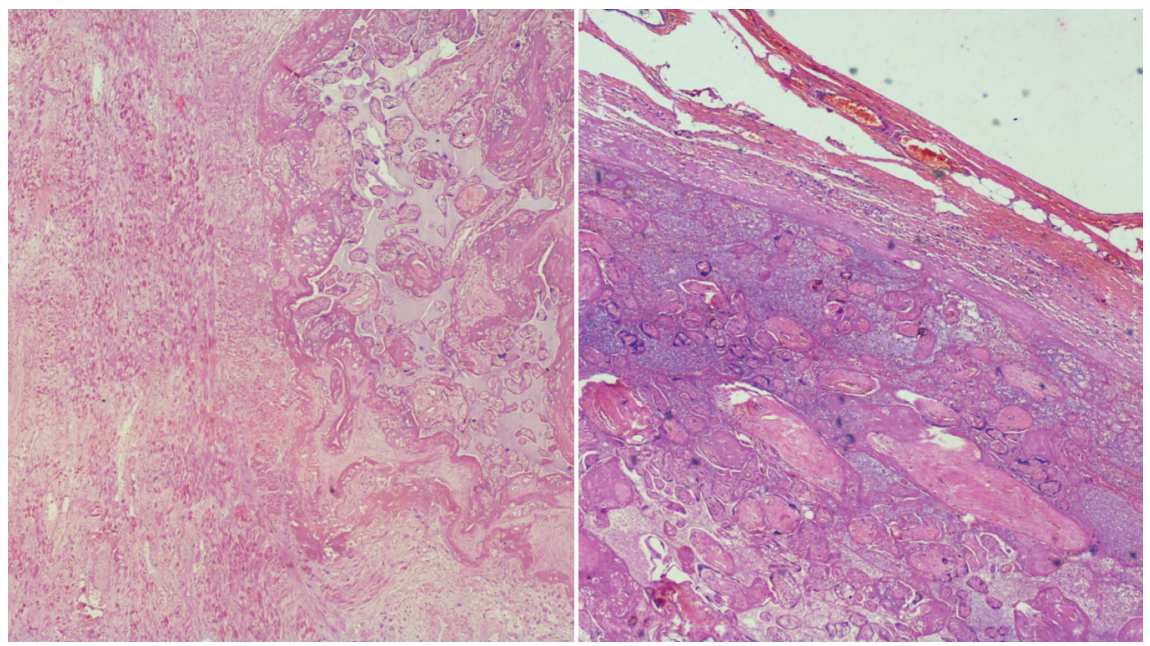

Figure 5. Hematoxylin and eosin (40x) stained sections of case 1, showing chorionic villi implanted into the myometrium without intervening decidua and full thickness invasion of the myometrium required more than four units of packed red blood cells. In comparison, blood loss during immediate cesarean In embolized patients (cases 1,2,3,5,6), the median (interquartile range) blood loss during CD was 200 (165-200) $\mathrm{mL}$ and during delayed elective hysterectomy (case 1,3,5) was 150 (range: 125-225 mL). Blood loss in case 2 was 1,000 mL during emergency hysterectomy on the seventh day after CD and UAE. Intraoperative blood loss and requirement for blood and blood products are shown in Table 1.

Figure 4 shows uterine specimens of cases 1 and 2 at the time of delayed hysterectomy, significantly regressed in size and vascularity. All seven patients did well in their postoperative period. The final diagnosis of percreta was confirmed by histopathology. Figure 5 shows the histopathological image of case 1 .

Using this planned multidisciplinary team approach, a good maternal and fetal outcome was achieved. hysterectomy in an embolized patient (case 4) was 1,700 mL. 


\section{Discussion}

The optimal management of placenta percreta is not yet clear. A wide array of management options have been discussed in the literature, yet no preferred management modality has been identified, possibly due to the low incidence of such cases. There is an ongoing debate whether to go for cesarean hysterectomy or conservative management leaving placenta in situ with or without elective delayed hysterectomy.

Cesarean hysterectomy in cases of placenta percreta is associated with high rates of severe maternal morbidity (40-50\%) and mortality (7\%) (7). Similarly, high maternal morbidity (56\%) during conservative management of placenta percreta has been reported by Matsuzaki et al. (9) in a systemic review. Massive hemorrhage and urinary tract injury are the most worrisome complications of cesarean hysterectomy, whereas the conservative approach is associated with late complications of leaving the placenta in situ. These late complications include secondary PPH, infection, DIC and need for an emergency hysterectomy (10). Therefore, detailed counseling of the patients, informed consent, and multidisciplinary approach for management is mandatory in these cases for an optimum outcome. We performed delayed hysterectomy wherever feasible, to avoid complications related to both approaches. Delaying hysterectomy might result in decreased uterine blood flow and regression of placenta from surrounding structures. UAE was also performed in most of the cases to minimize hemorrhage.

The exact time to perform delayed hysterectomy is debatable. The timing of elective delayed hysterectomy in our study was after 2-4 weeks following CD. In contrast, Zuckerwise et al. (7) suggested that the ideal time for hysterectomy was after 4-6 weeks subsequent to CD. However, Collins et al. (11) suggested re-evaluation of the time of delayed hysterectomy as they hypothesized that if the patient remains stable after 4-6 weeks of $\mathrm{CD}$, hysterectomy may not be needed. The International Society for Abnormally Invasive Placenta also documented no added advantage of elective delayed hysterectomy, and the associated potential risks of a second elective surgery in a stable patient (12). Similarly, Matsuzaki et al. (13) reported spontaneous placental absorption in $80 \%$ of cases after 4-6 weeks of $\mathrm{CD}$ during a conservative approach and suggested that elective hysterectomy may not be required after 4-6 weeks of $\mathrm{CD}$. However, $10 \%$ of conservatively managed cases had a massive hemorrhage, and 10\% of cases developed fistula formation, arteriovenous malformation, and DIC leading to emergency hysterectomy (13). Hence, the questions "whether to plan for elective delayed hysterectomy or not" and "when" are still unanswered.

In our experience, patients who underwent planned elective surgery had lesser blood loss and morbidity than emergency surgery. Silver et al. (14) also documented better maternal outcomes with elective surgeries.

We experienced appreciably higher blood loss in patients who underwent immediate cesarean hysterectomy compared to planned delayed hysterectomy. Likewise, Zuckerwise et al. (7) reported significantly high median estimated blood loss (EBL) with immediate hysterectomy (3,000 mL) compared to a delayed hysterectomy $(1,300 \mathrm{~mL})$ in placenta percreta cases. The requirement of transfusion of $>4$ units of RBC was also significantly higher in cases of immediate cesarean hysterectomy compared with delayed hysterectomy $(p=0.016)$.

Ouerdiane et al. (15) in their prospective study on conservative management of placenta percreta, where no additional therapy was used, reported that almost $31 \%$ of cases were complicated by massive obstetric hemorrhage or infection and required an emergency hysterectomy. In such a scenario, the role of a conservative approach with additional procedures such as injection methotrexate and UAE to decrease vascularity may be considered as a safe management option. This further paves the way for a technically easier planned delayed hysterectomy with a reduced rate of peri- and post-operative complications. The efficacy of methotrexate is questionable in late pregnancy, as it acts only on proliferative cells and trophoblastic proliferation is absent in late pregnancy (16). Moreover, the adverse effects of the drug itself have led to discouragement in its use, whereas selective arterial embolization is reported to have a $90 \%$ success rate in cases of PAS disorders (17).

In our experience, patients who underwent UAE had a better outcome in terms of intraoperative blood loss and the requirement of blood and blood products. Although we had planned delayed hysterectomy from 2-4 weeks after CD and UAE, 2/6 patients required emergency hysterectomy. Nevertheless, the overall EBL was notably lower in them than the patient who could not receive UAE.

Wang et al. (18) also described significantly less EBL, need for blood transfusion, and length of ICU stay with UAE before hysterectomy than cesarean hysterectomy alone. On the contrary, Matsuzaki et al. (9) reported no benefit of prophylactic UAE to improve success rates, although they documented earlier placental resorption with UAE when compared to no UAE (22.4 weeks vs 35.3 weeks; $\mathrm{p}=0.014$ ). Prophylactic devascularization, either surgically or radiologically, is expected to reduce intra-operative blood loss, secondary hemorrhage, and accelerate placental resorption $(19,20)$.

Internal iliac artery balloon occlusion has also been found to minimize blood loss (21). Cali et al. (22) also documented a statistically significant reduction in mean EBL (933 vs $1507 \mathrm{cc}$ ). In contrast, Salim et al. (23) demonstrated no difference in mean EBL with internal iliac artery balloon occlusion in women undergoing $\mathrm{CD}$ for suspected PAS. In a review article, Kingdom 
et al. (24) stated that with surgical expertise, balloon placement and devascularization do not improve patient outcomes. Additionally, it is highly demanding in terms of cost and hospital resources. Furthermore, vessel occlusion itself could pose certain complications such as hampered blood supply to lower limbs and pelvis (25), buttock necrosis (26), post embolization syndrome, uterine scarring, and secondary amenorrhea (27). We did not have any UAE-related complications in our case series.

Ligation of the anterior division of internal iliac arteries during surgery is another option although this is more surgically demanding. However, Hussein et al. (28) in a randomized trial reported no additional advantage of prophylactic internal iliac artery ligation during cesarean hysterectomy. It is well known that the blood supply of the lower uterine segment, paravesical spaces, and vagina comes from both internal iliac arteries and collaterals of external iliac arteries in percreta cases. Kingdom et al. (24) further proposed a five step approach to cesarean hysterectomy which leads to a mean EBL of less than 1.5 liters.

In the literature review, other alternatives described to minimize intra-operative blood loss were balloon placement in the infra-renal aortic and common iliac arteries. Li et al. (29) did a retrospective study to compare outcomes of all three levels of balloons (infra-renal aortic, common iliac and anterior divisions of the internal iliac arteries) in women with suspected PAS and concluded that surgery with balloons placed in the infra-renal aorta or common iliac arteries had significantly lower mean blood loss $(1,000 \mathrm{~mL})$ than surgery with internal iliac artery balloons $(2,900 \mathrm{~mL})$ and significantly lower rates of hysterectomy.

The rationale behind prophylactic devascularization (UAE) in our cases was to minimize intraoperative hemorrhage and associated morbidity whereas delayed hysterectomy was performed to avoid late complications of placenta left in situ. Our approach aimed to obviate the drawbacks of both a conservative approach and primary cesarean hysterectomy. Given the fact that most of our patients had completed their family and were not eager for uterine conservation, we could use this combined approach to ensure the least morbid management. Furthermore, one of our patients wished to conserve her uterus and fortunately had no postoperative complications after $\mathrm{CD}$ and UAE. Embolization techniques can also be used with a conservative approach. However, the preference of management options should be individualized until we have a consensus on the optimum approach for management. We performed delayed hysterectomy 2-4 weeks after $\mathrm{CD}$, which is quite early compared to other reports. A welldesigned, multicentre, randomized, controlled trial with a large sample size is needed for further validation.

\section{Conclusion}

Placenta percreta, if not managed in a preplanned manner, may lead to disastrous maternal outcomes. Prophylactic devascularization along with cesarean delivery and leaving the placenta in situ, followed by elective delayed hysterectomy might be a reasonable management option in most severe cases of placenta percreta.

Ethics Committee Approval: The study was reviewed and approved by the Institutional Ethical Committee (approval number: AIIMS/IEC/20/341) of All India Institute of Medical Sciences Rishikesh.

Informed Consent: A written and informed consent was taken from all patients.

Peer-review: Externally peer-reviewed.

Author Contributions: Surgical and Medical Practices: K.K., A.G., O.K., D.K., P.S., R.B., J.C.; Concept: K.K., J.C.; Design: K.K., D.K., A.G.; Data Collection or Processing: K.K., D.K., O.K.; Analysis or Interpretation: K.K., D.K., P.S.; Literature Search: K.K., D.K.; Writing: K.K., D.K.

Conflict of Interest: All author's declare no conflict of interest.

Financial Disclosure: The authors declared that this study received no financial support.

\section{References}

1. Morlando M, Sarno L, Napolitano R, Capone A, Tessitore G, Maruotti GM, et al. Placenta accreta: incidence and risk factors in an area with a particu-larly high rate of cesarean section. Acta Obstet Gynecol Scand 2013; 92: 457-60.

2. Miller DA, Chollet JA, Goodwin TM. Clinical risk factors for placenta previa-placenta accreta. Am J Obstet Gynecol 1997; 177: 210-4.

3. Royal College of Obstetricians and Gynecologists. Placenta Praevia and Placenta Accreta: Diagnosis and Management (Green-top Guideline No. 27a). London: RCOG; 2018.

4. Jauniaux E, Alfirevic Z, Bhide AG, Belfort MA, Burton GJ, Collins SL, et al. Placenta Praevia and Placenta Accreta: Diagnosis and Management: Green-top Guideline No. 27a. BJOG 2019; 126: e1-e48.

5. Cahill AG, Beigi R, Heine RP, Silver RM, Wax JR. Placenta accreta spectrum. Am J Obstet Gynecol 2018; 219: B2-16.

6. Clausen C, Lönn L, Langhoff-Roos J. Management of placenta percreta: a review of published cases. Acta Obstet Gynecol Scand 2014; 93: 138-43.

7. Zuckerwise L, Craig A, Newton J, Zhao S, Bennett K, Crispens M. Outcomes following a clinical algorithm allowing for delayed hysterectomy in the management of severe placenta accreta spectrum. Am J Obstet Gynecol 2020; 222: 179.e1-179.e9.

8. Kotsuji F, Nishijima K, Kurokawa T, Yoshida Y, Sekiya T, Banzai M, et al. Transverse uterine fundal incision for placenta praevia with accreta, in-volving the entire anterior uterine wall: a case series. BJOG 2013; 120: 1144-9. 
9. Matsuzaki S, Yoshino K, Endo M, Kakigano A, Takiuchi T, Kimura T. Conservative management of placenta percreta. Int J Gynaecol Obstet 2018; 140: 299-306.

10. Luo G, Perni S, Jean-Pierre C, Baergen R, Predanic M. Failure of conservative management of placenta previa-percreta. J Perinat Med 2005; 33: 564-8.

11. Collins SL, Sentilhes L, Chantraine F, Jauniaux E. Delayed hysterectomy: a laparotomy too far? Am J Obstet Gynecol 2020; 222: 101-2.

12. Collins SL, Alemdar B, van Beekhuizen HJ, Bertholdt C, Braun T, Calda $\mathrm{P}$, et al. Evidence-based guidelines for the management of abnormally inva-sive placenta: recommendations from the International Society for Abnormally Invasive Placenta. Am J Obstet Gynecol 2019; 220: 511-26.

13. Matsuzaki S, Grubbs BH, Matsuo K. Delayed hysterectomy versus continuing conservative management for placenta percreta: which is better? Am J Obstet Gynecol 2020; 223: 304.

14. Silver RM, Fox KA, Barton JR, Abuhamad AZ, Simhan H, Huls CK, et al. Center of excellence for placenta accreta. Am J Obstet Gynecol 2015; 212: 561-8.

15. Ouerdiane N, Daaloul W, Othmani K, Masmoudi A, Hamouda S, Bouguerra B. Conservative management of placenta percreta: tunisian prospective study. Gynecol Obstet Case Rep 2016; 2: 2.

16. Timmermans S, van Hof A, Duvekot J. Conservative management of abnormally invasive placentation. Obstet Gynecol Surv 2007; 62: 529-39.

17. Mei J, Wang Y, Zou B, Hou Y, Ma T, Chen M, et al. Systematic review of uterus-preserving treatment modalities for abnormally invasive placenta. J Obstet Gynaecol 2015; 35: 777-82.

18. Wang M, Ballah D, Wade A, Taylor AG, Rizzuto G, Li B, et al. Uterine artery embolization following cesarean delivery but prior to hysterectomy in the management of patients with invasive placenta. J Vasc Interv Radiol 2019; 30: 687-91.

19. Bouvier A, Sentilhes L, Thouveny F, Bouet PE, Gillard P, Willoteaux $\mathrm{S}$, et al. Planned cesarean in the interventional radiology cath lab to enable immediate uterine artery embolization for the conservative treatment of placenta accreta. Clin Radiol 2012; 67: 1089-94.

20. Soyer P, Sirol M, Fargeaudou Y, Bour L, Morel O, Dohan A, et al. Placental vascularity and resorption delay after conservative management of inva-sive placenta: MR imaging evaluation. Eur Radiol 2013; 23: 262-71.

21. Petrov DA, Karlberg B, Singh K, Hartman M, Mittal PK. Perioperative internal iliac artery balloon occlusion, in the setting of placenta accreta and its variants: the role of the interventional radiologist. Curr Probl Diagn Radiol 2018; 47: 445-51.

22. Cali G, Forlani F, Giambanco L, Amico ML, Vallone M, Puccio G, et al. Prophylactic use of intravascular balloon catheters in women with placenta accreta, increta and percreta. Eur J Obstet Gynecol Reprod Biol 2014; 179: 36-41.

23. Salim R, Chulski A, Romano S, Garmi G, Rudin M, Shalev E. Precesarean prophylactic balloon catheters for suspected placenta accreta: a randomized controlled trial. Obstet Gynecol 2015; 126 : 1022-8.

24. Kingdom JC, Hobson SR, Murji A, Allen L, Windrim RC, Lockhart $\mathrm{E}$, et al. Minimizing surgical blood loss at cesarean hysterectomy for placenta previa with evidence of placenta increta or placenta percreta: the state of play in 2020. Am J Obstet Gynecol 2020; 223: 322-9.

25. Papillon-Smith J, Singh SS, Ziegler C. Internal iliac artery rupture caused by endovascular balloons in a woman with placenta percreta. J Obstet Gy-naecol Can 2016; 38: 1024-7.

26. Smith DD, Perez-Delboy A, Burke WM, Tergas AI. Buttock necrosis after uterine artery embolization for delayed hysterectomy in placenta percreta. Case Rep Obstet Gynecol 2016; 2016: 6921280.

27. Alanis M, Hurst B, Marshburn P, Matthews M. Conservative management of placenta increta with selective arterial embolization preserves future fertility and results in a favorable outcome in subsequent pregnancies. Fertil Steril 2006; 86: 1514.e37.

28. Hussein AM, Dakhly DMR, Raslan AN, Kamel A, Hafeez AA, Moussa $\mathrm{M}$, et al. The role of prophylactic internal iliac artery ligation in abnormally invasive placenta undergoing cesarean hysterectomy: a randomized control trial. J Matern Fetal Neonatal Med 2019; 32: 3386-92.

29. Li K, Zou Y, Sun J, Wen H. Prophylactic balloon occlusion of internal 442 iliac arteries, common iliac arteries and infrarenal abdominal aorta in preg-nancies complicated by placenta accreta: a retrospective cohort study. Eur Radiol 2018; 28: 4959-67. 